\title{
Lack of mutations in the PVRL3 gene in North American Caucasians with non-syndromic cleft lip/palate
}

\author{
Mehmet A. Sözen ${ }^{1,3}$, Jacqueline T. Hecht ${ }^{2}$ and Richard A. Spritz ${ }^{3}$ \\ ${ }^{1}$ Department of Medical Biology, School of Medicine, Afyon Kocatepe University, Afyonkarahisar, Turkey. \\ ${ }^{2}$ Department of Pediatrics, University of Texas Medical School, Houston, Texas, USA. \\ ${ }^{3}$ Human Medical Genetics Program, University of Colorado Denver, Anschutz Medical Campus, Aurora, \\ Colorado, USA.
}

\begin{abstract}
Cleft lip with or without cleft palate (CLP) is one of the most common birth defects. In about $70 \%$ of cases, CLP occurs as an isolated anomaly, denoted non-syndromic CLP (nsCLP). Genetic linkage and association studies have implicated many loci in susceptibility to nsCLP, including some members of the nectin gene family. We performed mutation screening of the PVRL3 gene that encodes nectin-3 in 73 unrelated Caucasian nsCLP patients and 105 unrelated controls from North America. We detected no sequence variants in the PVRL3 gene in either the nSCLP patients or the controls. These data suggest that PVRL3 is not an important susceptibility gene for nsCLP in the North American Caucasian population.
\end{abstract}

Key words: orofacial clefts, nectins, PVRL3, mutation analysis.

Received: November 27, 2007; Accepted: February 29, 2008.

Cleft lip with or without cleft palate (CLP; MIM $119530)$ is among the most common birth defects, occurring in most populations in about 0.2 to 3 per 1000 liveborn infants (Schutte and Murray, 1999; Spritz, 2001; Cobourne, 2004). In about $30 \%$ of cases, CLP occurs as part of heritable Mendelian syndromes, but in the majority of cases it occurs as an isolated, complex trait, denoted non-syndromic CLP (nsCLP). Genetic linkage and association studies have implicated many loci in the pathogenesis of nsCLP, including PVRL1, which encodes nectin-1, a cell adhesion molecule (Reymond et al., 2000; Satoh-Horikawa et al., 2000). Homozygous loss-of-function mutations in PVRL1 result in a rare recessive CLP syndrome, CLPED1 (Suzuki et al., 2000), and heterozygous PRVL1 variants have been associated with nsCLP (Sozen et al., 2001; Turhani et al., 2005; Avila et al., 2006; Neiswanger et al., 2006; Scapoli et al., 2006; Tseng et al., 2006).

Two other nectin-family paralogues, $P V R$ and $P V R L 2$, were recently evaluated as candidate genes for nsCLP and found to show evidence of genetic association (Warrington et al., 2006). Here, we describe the analysis of another member of the nectin gene family, PVRL3, which encodes nectin-3, as a candidate gene for nsCLP. PVRL 3 is

Send correspondence to Mehmet Ali Sözen. Department of Medical Biology, School of Medicine, Afyon Kocatepe University, 03200 Poliklinikler Binasi, Afyonkarahisar, Turkey. E-mail: aijmasozen@ hotmail.com. expressed mainly in testis and placenta, and at a lower level in heart, brain, lung, liver, and kidney (Reymond et al., 2000; Satoh-Horikawa et al., 2000). It is located on chromosome 3q13.13, which has not been implicated in the pathogenesis of nsCL/P so far.

We screened for variants in the six coding exons of the PVRL3 gene and adjacent intron and non-coding sequences in 73 unrelated North American Caucasian patients with nsCLP (33 from Texas, 20 from Maryland, 20 from Ohio) and 100 unrelated Caucasian unaffected controls, using the single-stranded conformation polymorphism (SSCP)/heterduplex technique (Lee et al., 1995). Exon 6 was divided into two overlapping amplicons, 6A and $6 \mathrm{~B}$. PCR and sequencing primers were:

Exon 1, 5'-AGCGTTCGGCCAAGTGTCAG-3' / 5'TCCAGAGAACGGCTGGCAGA-3'; Exon 2, 5'-GAAG GGAGGAGAGTGTTGAC-3' / 5'-CTTCACCACTATC ACCAAAATAC-3'; Exon 3, 5'-GCAGTTGTCCTTAAG CTTGTG-3'/5'-AGTTTGATAAACATGCTGAC-3'; Exon 4, 5'-GTAATCTGTCCTGTCATGC-3' / 5'-CTGCTCC ACACAGATTTGA-3'; Exon 5, 5'-CAGTGAATTTTGT CTGAGATGC-3' / 5'-CTCATTTTGCAAGCAGATA G3'; Exon 6A, 5'-GCCTTTCTGTGTCTTCTCTA-3' / 5'-A CACTGTCTGGGTAAGAATC-3'; Exon 6B, 5'-CATTC CACCATCAGATATGC-3' / 5'-CTAGTGTGAATGAA CATTGTAC-3'. All genomic DNA samples were obtained with informed consent. 
We observed no sequence variations in the regions of PVRL3 examined, in either patients or controls. It is possible that some variants were not detected by the $\mathrm{SSCP} /$ heteroduplex screening method used; nevertheless, only two verified SNPs have been observed in PVRL3 exonic regions in Caucasians, rs15611 and rs34163852, both with very low minor allele frequencies (Ensembl), and neither of these was observed here. Although we cannot rule out variation outside the genomic regions evaluated, our results do not support a significant role for PVRL3 in the pathogenesis of $\mathrm{nsCL} / \mathrm{P}$ in Caucasian populations.

\section{Acknowledgments}

This work was supported by National Institutes of Health grant DE13571 to R.A.S and DE011931 to J.T.H. We thank Dr. Iain MacIntosh and Dr. Jeffrey Murray for providing some of the patient and control DNA samples.

\section{References}

Avila JR, Jezewski PA, Vieira AR, Orioli IM, Castilla EE, Christensen K, Daack-Hirsch S, Romitti PA and Murray JC (2006) PVRL1 variants contribute to non-syndromic cleft lip and palate in multiple populations. Am J Med Genet A 140:2562-2570.

Cobourne MT (2004) The complex genetics of cleft lip and palate. Eur J Orthod 26:7-16.

Lee ST, Park SK, Lee KH, Holmes SA and Spritz RA (1995) A non-radioactive method for simultaneous detection of single-strand conformation polymorphisms (SSCPs) and heteroduplexes. Mol Cell 5:668-672.

Neiswanger K, Deleyiannis FWB, Avila JR, Cooper ME, Brandon CA, Vieira AR, Noorchashm N, Weinberg SM, Bardi KM, Murray JC, et al. (2006) Candidate genes for oral-facial clefts in Guatemalan families. Ann Plast Surg 56:518-521.

Reymond N, Borg JP, Lecocq E, Adelaide J, Campadelli-Fiume G, Dubreuil P and Lopez M (2000) Human nectin3/PRR3: A novel member of the PVR/PRR/nectin family that interacts with afadin. Gene 255:347-355.

Satoh-Horikawa K, Nakanishi H, Takahashi K, Miyahara M, Nishimura M, Tachibana K, Mizoguchi A and Takai Y
(2000) Nectin-3, a new member of immunoglobulin-like cell adhesion molecules that shows homophilic and heterophilic cell-cell adhesion activities. J Biol Chem 275:1029110299.

Scapoli L, Palmieri A, Martinelli M, Vaccari C, Marchesini J, Pezzetti F, Baciliero U, Padula E, Carinci P and Carinci F (2006) Study of the PVRL1 gene in Italian nonsyndromic cleft lip patients with or without cleft palate. Ann Hum Genet 70:410-413.

Schutte BC and Murray JC (1999) The many faces and factors of orofacial clefts. Hum Mol Genet 8:1853-1859.

Sözen MA, Suzuki K, Tolarova MM, Bustos T, Fernandez Iglesias JE and Spritz RA (2001) Mutation of PVRL1 is associated with sporadic, non-syndromic cleft lip/palate in northern Venezuela. Nat Genet 29:141-142.

Spritz RA (2001) The genetics and epigenetics of orofacial clefts. Curr Opinion Pediatr 13:556-560.

Suzuki K, Hu D, Bustos T, Zlotogora J, Richieri-Costa A, Helms JA and Spritz RA (2000) Mutations of PVRL1, encoding a cell-cell adhesion molecule/herpesvirus receptor, in cleft lip/palate-ectodermal dysplasia. Nat Genet 25:427-430.

Tseng Y-T, Hsiao H-H, Hsiao H-P, Tsai W-C and Chiu H-H (2006) A study of PVRL1 mutations for non-syndromic cleft lip and/or palate among Taiwanese patients. Int J Oral Maxillofac Surg 35:453-455.

Turhani D, Item CB, Watzinger E, Sinko K, Watzinger F, Lauer G and Ewers R (2005) Mutation analysis of CLPTM1 and $P V R L 1$ genes in patients with non-syndromic clefts of lip, alveolus and palate. J Craniomaxillofac Surg 33:301-306.

Warrington A, Vieira AR, Christensen K, Orioli IM, Castilla EE, Romitti PA and Murray JC (2006) Genetic evidence for the role of loci at 19q13 in cleft lip and palate. J Med Genet 43:e26.

\section{Internet Resources}

Ensembl, http://www.ensembl.org/Homo_sapiens/geneview? gene $=$ ENSG00000177707.

Associate Editor: Paulo A. Otto

License information: This is an open-access article distributed under the terms of the Creative Commons Attribution License, which permits unrestricted use, distribution, and reproduction in any medium, provided the original work is properly cited. 